\title{
Chemical resistance/thermal and mechanical properties of unsaturated polyester-based nanocomposites
}

\author{
Y. Jaya Vinse Ruban • S. Ginil Mon • \\ D. Vetha Roy
}

Received: 12 November 2012/ Accepted: 4 January 2013/Published online: 31 January 2013

(C) The Author(s) 2013. This article is published with open access at Springerlink.com

\begin{abstract}
Nanocomposites were synthesized using unsaturated polyester as the matrix and organically modified montmorillonite (CA-MMT) as the reinforcing agent. XRD pattern of the modified montmorillonite showed that the interlayer spacing expanded from 1.21 to $1.9 \mathrm{~nm}$, indicating intercalation. TGA and DTA show loss of organic surfactant from interlayer galleries. Glass transition temperature $\left(T_{\mathrm{g}}\right)$ of these composites increased from $71{ }^{\circ} \mathrm{C}$ in the unfilled unsaturated polyester to $79{ }^{\circ} \mathrm{C}$ in the composites with $5 \%$ organically modified montmorillonite. Chemical resistance and mechanical properties of the UP/organo-clay nanocomposites were studied. Chemical resistance was studied under aqueous conditions in acetic acid, nitric acid, hydrochloric acid, sodium hydroxide, aqueous ammonia and sodium carbonate. Chemical resistance studies reveal maximum weight gain/loss with increasing clay content. Mechanical studies show maximum characteristics for the composites-clay filled $5 \%$ (w/w).
\end{abstract}

Keywords Unsaturated polyester - Montmorillonite · Nanocomposites - Thermal and mechanical properties . Chemical resistance

Y. Jaya Vinse Ruban ( $₫)$

Department of Chemistry and Research, St. Xavier's College (Autonomous), Palayamkottai, Tirunelveli, India

e-mail: jayavinse@gmail.com

S. Ginil Mon

Department of Chemistry and Research, Nesamony Memorial Christian College, Marthandam 629165, India

D. Vetha Roy

Department of Chemistry and Research, Polymer

Nanocomposite Centre, Scott Christian College (Autonomous),

Nagercoil 629003, Tamilnadu, India

\section{Introduction}

Polymer nanocomposites, especially polymer-layered silicate nanocomposites, represent a rational alternative to conventionally filled polymers. Because of their nanodispersion, they exhibit markedly improved properties when compared with the pure polymers of conventional composites. The ideal composite material is thought to be a dispersion of rigid-rod like molecules in a flexible polymer matrix, i.e., a molecular composite (Lee et al. 2004). In general, there are two methods of making nanocomposites, melt intercalation and in situ intercalative polymerization of monomers. Melt intercalation of high polymers is a powerful new approach for synthesizing polymer-layered silicate nanocomposites. This method is quite common, broadly applicable to many commodity polymers, from non-polar polystyrene, weakly polar PET to strongly polar nylon (Suh et al. 2000).

Thermoset matrices offer a wide range of industrial applications such as adhesives and coatings to electrical insulators and matrix resins for advanced structural composites. Most common thermoset polymers are epoxides and styrenated unsaturated polyesters, though epoxy-based nanocomposites are extensively investigated (MironiHarpaz et al. 2005). Among various thermoset resins, unsaturated polyester resins are the most widely used matrix materials in polymeric composites. They represent approximately $75 \%$ of the total thermoset composites, marked in tonnage (Mark et al. 1988).

The cross-linking reaction of polyester resins is a free radical chain growth co-polymerization. The polyester oligomer provides cross-linking points for network formation, while the styrene monomer provides linear chain extension (Liqun and James Lee 2005). A mechanism was proposed to describe the cross-linking behavior of 
polyester resins in five steps, including induction, microgel formation, transition with or without phase separation, macrogelation and post-gelation. A more detailed description of the mechanism of free radical co-polymerization of UP/styrene resins can be found elsewhere (Liqun and James Lee 2005). However, the free radical copolymerization of UP resin and styrene leads to a high degree of polymerization shrinkage, about $7-10 \%$, which often causes severe surface quality and dimension control problems during manufacturing (Liqun and James Lee 2004).

Ismail et al. investigated the effect of clay particle size on the mechanical properties of UP-sand/clay composites (Xiao-An and Qutubuddin 2004), which shows that the compressive strength increased, while the water absorption decreased with increasing clay particle size. The UP-clay nanocomposites were synthesized by Kornmann et al. (1998) and Suh et al. (2000) with intercalated polymerclay nanocomposites formed by the insertion of one or more macromolecular layers into the clay host-galleries. These exfoliated polymer-clay nanocomposites are characterized by the low clay content, a monolithic structure and a separation between the clay layers that depend on polymer content of nanocomposites. The exfoliation of clay nanolayers in a polymer matrix has improved various characteristics of polymer nanocomposites.

The objective of the present study is to synthesize modified MMT-UP composites and to investigate the effect of extent of modification on MMT, in the chemical resistance, thermal and mechanical properties of UP composites.

\section{Experimental}

\section{Materials}

Unsaturated polyester resin (isophthalic acid based) with viscosity 2,300-2,400 cP, and $\mathrm{OH}$ index $24.4 \mathrm{eq} / \mathrm{kg}$, analytical grade methylethylketone peroxide (MEKP) and cobalt octanate were supplied by Polyresins, India. Montmorillonite clay was purchased from Sigma Aldrich Inc., USA. Tetradecyltrimethylammonium bromide was kindly supplied by Sisco Research Laboratories, Mumbai, sodium chloride was provided by Central Drug House, New Delhi, and silver chloride was purchased from Merck India Ltd., India. Double distilled water was used throughout the study.

Purification of montmorillonite (MMT)

The purification of MMT was achieved by sedimentation, centrifugation and drying following standard methods (Kornmann et al. 1998). A portion of the MMT was crushed in an agate mortar in order to obtain a fine powder. The clay was dispersed in deionised water in an ultrasonic bath for $10 \mathrm{~min}$. The obtained solution was stirred overnight, the sediments discarded and the syrupy liquid containing product in suspension (which are less than $\approx 2 \mu \mathrm{m}$ ) was subjected to $5,000 \mathrm{rpm}$ for $15 \mathrm{~min}$ when the product sedimented rapidly in the centrifugal field. Particles were quickly redispersed in double distilled water. The concentrated solution obtained was dried at $50{ }^{\circ} \mathrm{C}$ in a ventilated oven for 4 days.

\section{Preparation of Na-montmorillonite}

In order to enhance the swelling properties of MMT, sodium activation was performed by dispersing $25 \mathrm{~g}$ of MMT in $5 \mathrm{~L}$ of $1 \mathrm{~N}$ sodium chloride solution with stirring. The stirring was continued for $24 \mathrm{~h}$ at $70{ }^{\circ} \mathrm{C}$. Upon centrifugation of the solution at high speed, an opaque layer accumulated in the bottom of the centrifuge tubes beneath a translucent gel. The gel was isolated and washed several times with distilled water until no chloride was detected in the centrifugate by testing with one drop of $0.1 \mathrm{~N}$ silver nitrate solution. The purified clay was dried at $70{ }^{\circ} \mathrm{C}$ and stored in a desiccator.

Intercalation of alkyl ammonium ions

The Na-exchanged MMT (15 g) was dispersed in 1,200 $\mathrm{mL}$ of distilled water at $80{ }^{\circ} \mathrm{C}$. Then $5.7 \mathrm{~g}$ of tetradecyltrimethylammonium bromide in $300 \mathrm{~mL}$ distilled water was introduced into the above hot solution and stirred vigorously for $1 \mathrm{~h}$ at $80{ }^{\circ} \mathrm{C}$. The white precipitate was washed several times with hot water/ethanol (1:1) mixture until no chloride was detected in the filtrate by one drop of $0.1 \mathrm{~N}$ silver nitrate solution. The alkylammoniumexchanged MMT was then dried several days at $75^{\circ} \mathrm{C}$, ground with agate mortar and then stored in a desiccator (Chozhan et al. 2007).

\section{Preparation of polymer nanocomposites}

Prior to nanocomposite fabrication, the alkylammoniumexchanged MMT were dried in vacuum at $60{ }^{\circ} \mathrm{C}$, overnight. Then the calculated amount of clay was dispersed with unsaturated polyester resin by mechanical stirring for $1 \mathrm{~h}$. After deaeration, the MEKP (1\% (w/w) in accordance with UP resin) catalyst was stirred with cobalt octanate accelerator $[0.5 \%(\mathrm{w} / \mathrm{w})$ in accordance with UP resin] for $3 \mathrm{~min}$. Then the deaerated mixture was poured into an open mould coated with a silicone-releasing agent. Curing was done at room temperature for $24 \mathrm{~h}$ followed by post curing at $80{ }^{\circ} \mathrm{C}$ for $6 \mathrm{~h}$ and $120{ }^{\circ} \mathrm{C}$ for $2 \mathrm{~h}$. The neat polyester composite was also prepared and used as standard. 


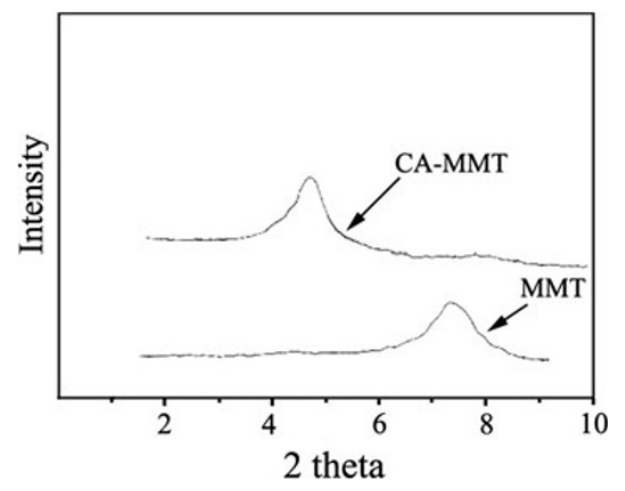

Fig. 1 XRDs of MMT and cetyl ammonium treated MMT

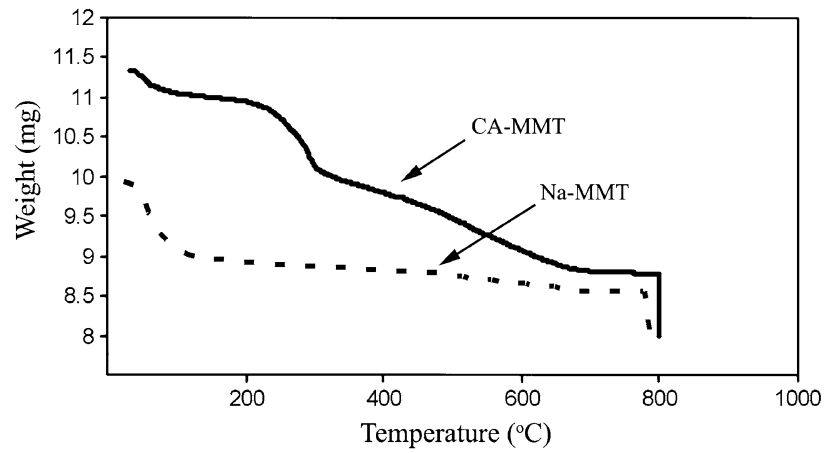

Fig. 2 TGA curve of Na-MMT and CA-MMT

\section{Chemical resistance}

The chemical resistance of the samples were studied in $8 \%$ acetic acid, $40 \%$ nitric acid, $10 \%$ hydrochloric acid, $10 \%$ aqueous ammonia, $20 \%$ sodium carbonate, $10 \%$ sodium hydroxide and water based on ASTM standards.

\section{Characterization}

$\mathrm{X}$-ray diffraction patterns were obtained by using a Rigaku $\mathrm{X}$-ray diffractometer, with $\mathrm{CuK} \alpha$ radiation and a curved graphite crystal monochromator, to compute the crystallographic spacing, $d$.

In order to evaluate the changes in the glass transition temperature $\left(T_{\mathrm{g}}\right)$ with increasing clay content, differential scanning calorimeter (DSC) analysis was carried out using a general V4.1C DuPont 2000 equipment. The measurements were carried out by heating from 30 to $250{ }^{\circ} \mathrm{C}$ at the rate $10{ }^{\circ} \mathrm{C} / \mathrm{min}$ under nitrogen atmosphere.

Tensile and flexural tests were performed by using INSTRON 3365, UK, testing machine. While tensile tests were done using ASTM-D3039 standard specimens with a cross head speed of $5 \mathrm{~mm} / \mathrm{min}$, flexural tests were done according to ASTM D720 using a cross head speed of $5 \mathrm{~mm} / \mathrm{min}$. Six samples were analyzed and their average was taken.

The resistance of the prepared composites to various chemicals is studied using ASTM D543-87 method (Annual book of ASTM standards 1989). In each case, ten pre-weighed samples were dipped in the respective chemicals for 1,7 and 15 days, removed immediately, washed with distilled water and dried by pressing them between the filter papers. The samples were then weighed and the percentage-weight change was determined.
Fig. 3 DTA curve of Na-MMT and CA-MMT

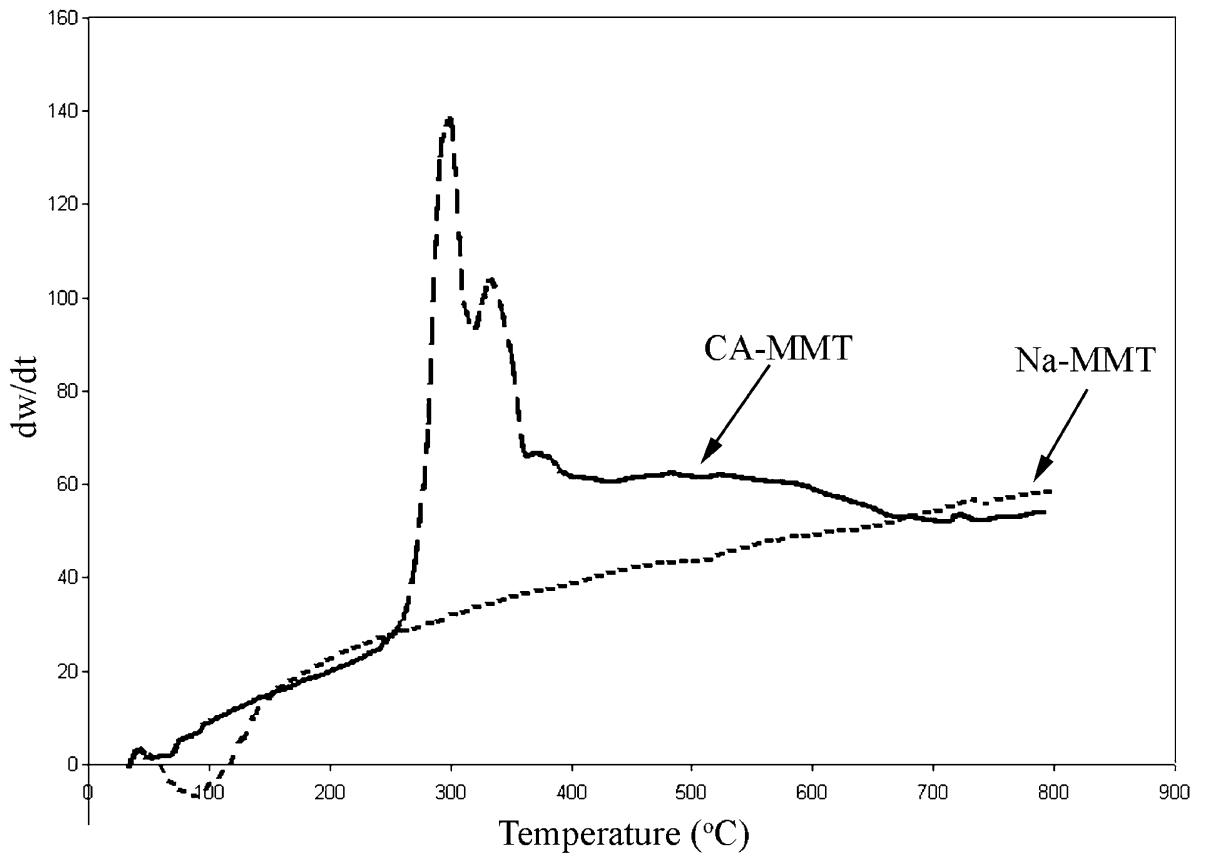

SACST Springer 
The surfaces were coated with gold and examined under a scanning electron microscope (CARL-ZEISS, Model EVO-50).

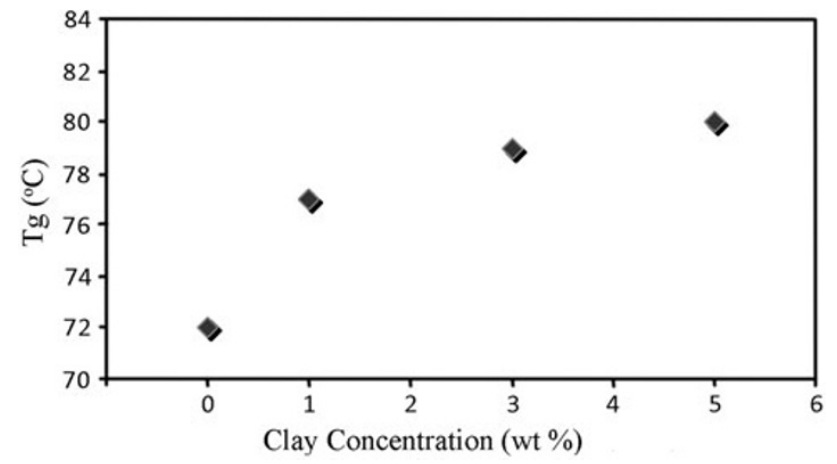

Fig. 4 Glass transition temperature of CA-MMT-polyester composites
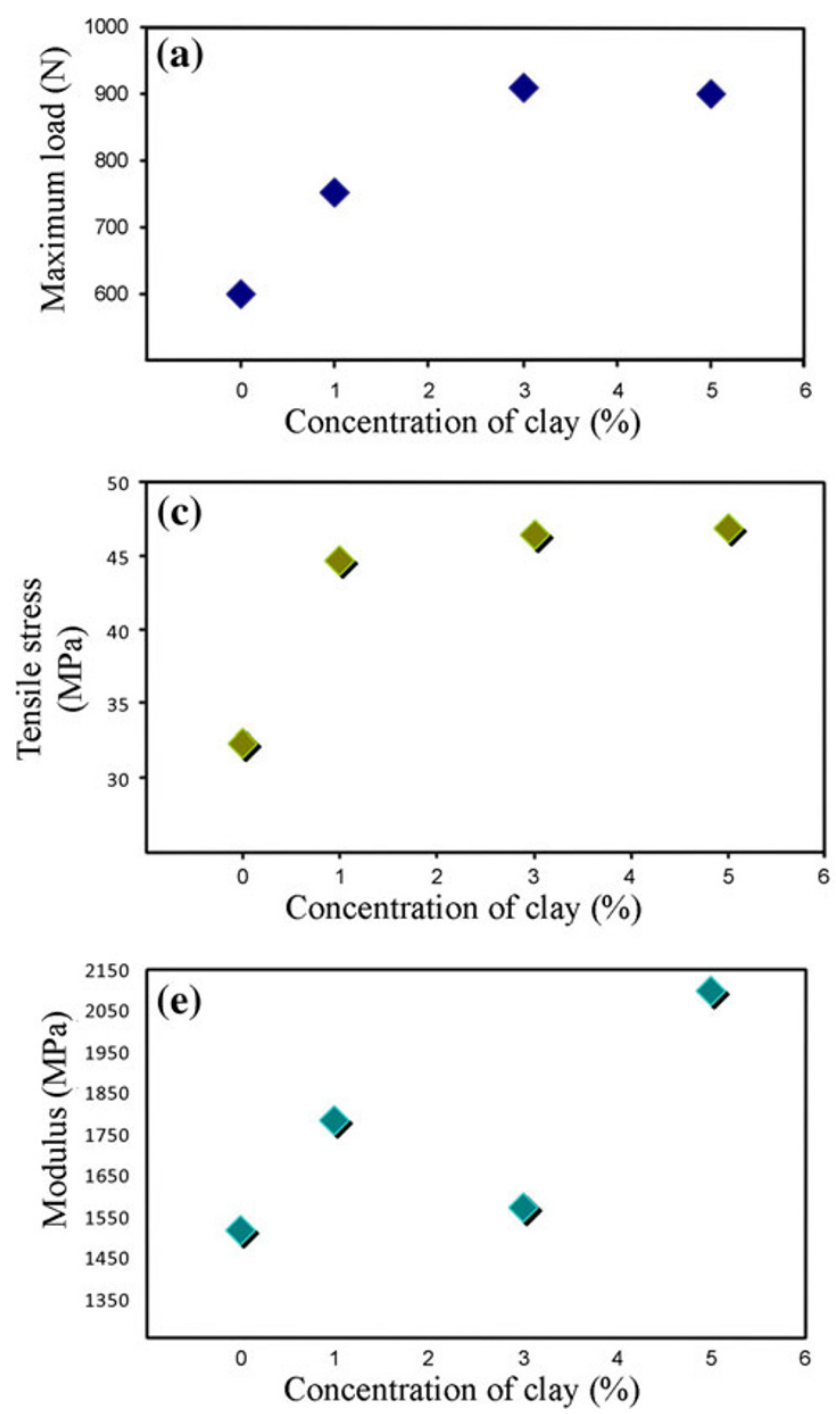

\section{Results and discussion}

Functionalization of MMT

Organophilic clay plays an important role in the preparation of polymer-clay nanocomposites. The ideal organoclay should have strong interactions with the selected polymer and should improve the interfacial adhesion between the organic and inorganic phases. After inorganic cations such as $\mathrm{Na}^{+}$and $\mathrm{Ca}^{2+}$ in the clay galleries are exchanged by organic cations, the clay is rendered hydrophobic and called organo-clay. In the present work, tetradecyltrimethylammonium bromide was used to prepare the organo-clay.

Figure 1 shows typical X-ray diffraction patterns of MMT and CA-MMT. The silicate layer (001) reflection of
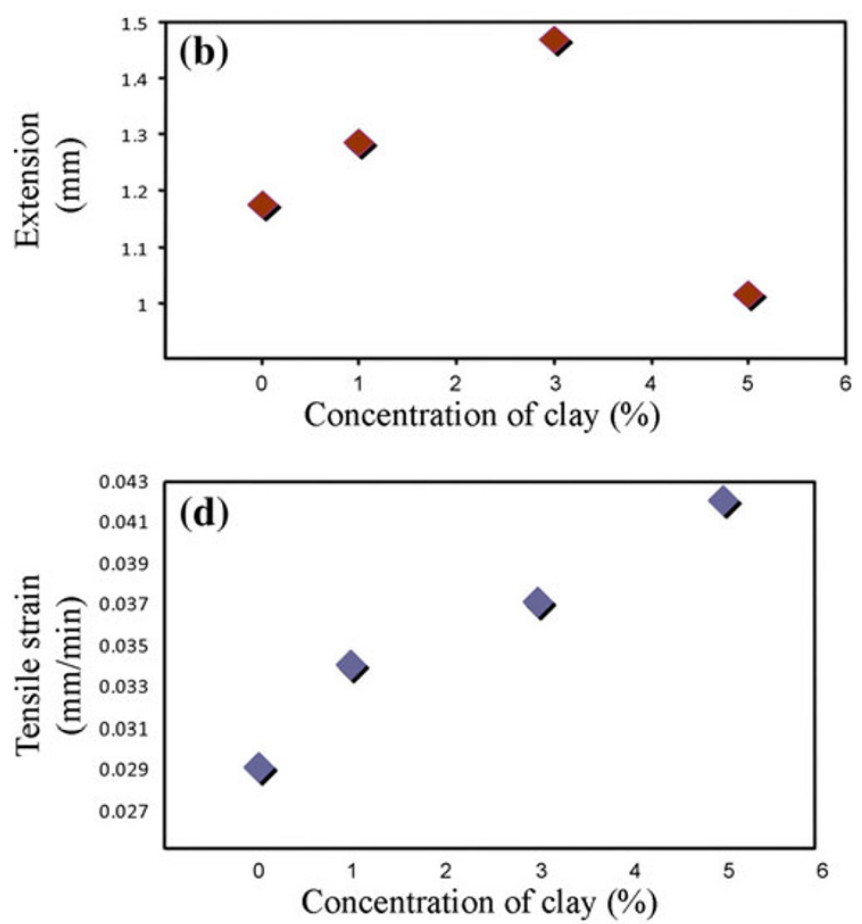

Fig. 5 Shows the variation of tensile properties against concentration of clay in $\%(w / w)$. a Maximum load at ultimate strength; b extension at ultimate strength; $\mathbf{c}$ tensile stress at ultimate strength; $\mathbf{d}$ tensile strain at ultimate strength; e modulus 

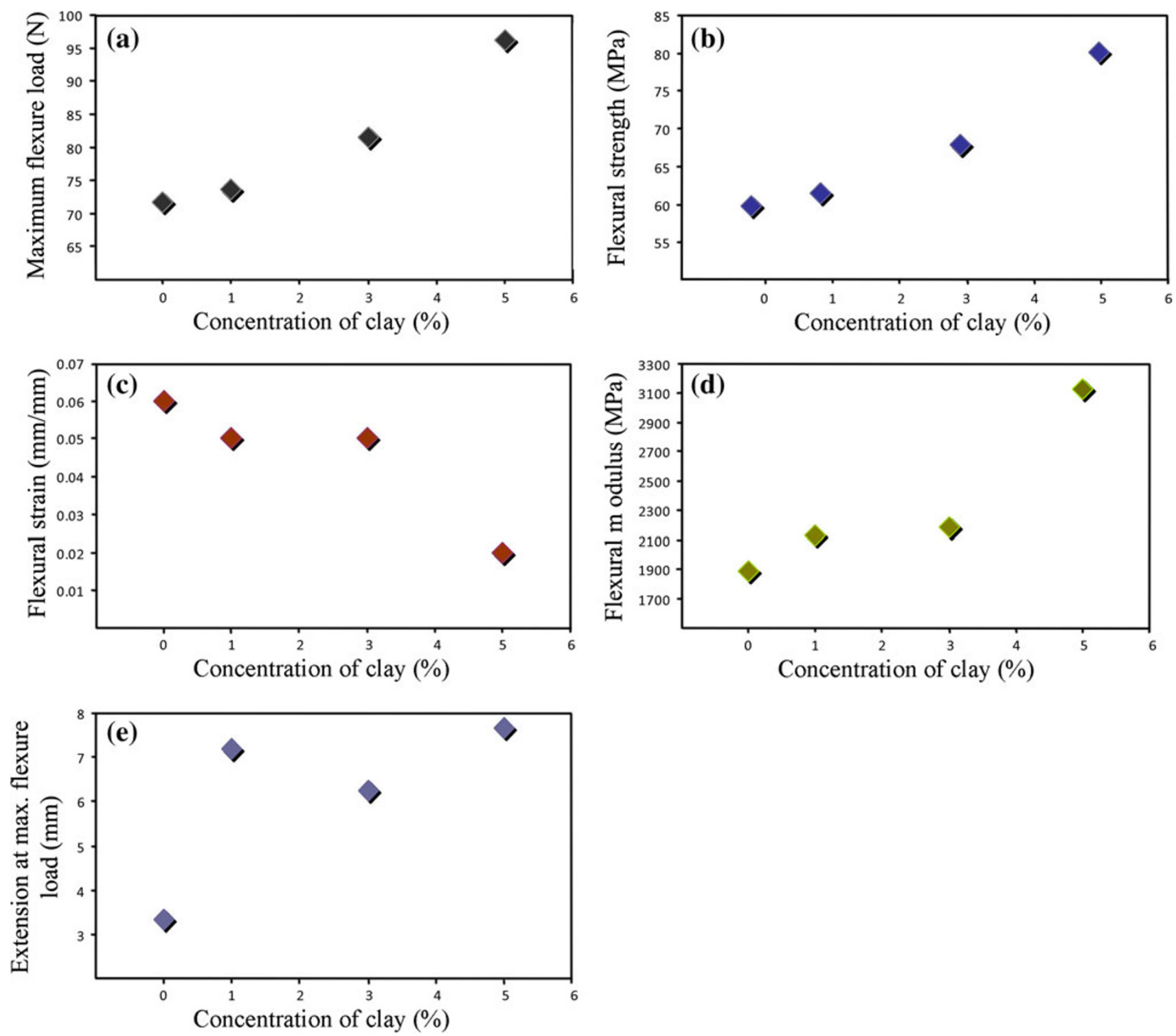

Fig. 6 Shows the variation of flexural properties against concentration of clay in $\%$ (w/w). a Maximum flexure load, b flexural strength, c flexural strain, $\mathbf{d}$ flexural modulus, e extension at maximum flexure load

MMT has a peak position at $2 \theta=7.35$ while for CAMMT; the peak position is at $2 \theta=4.7$. The $d_{001}$ spacing was calculated from peak positions using Bragg's law: $d=\lambda /(2 \sin \theta)$, where $\lambda$ is the X-ray wavelength. The $d_{001}$ spacing of MMT is $1.21 \mathrm{~nm}$ while that of CA-MMT is $1.9 \mathrm{~nm}$. The increase of interlayer spaces lowers the interlayer attraction force and facilitates the intercalation of UP (Tjong 2006).

The TGA and DTA curves of CA-MMT and Na-MMT are depicted in Figs. 2 and 3, respectively. TGA results of CA-MMT show $17 \%$ weight loss and the cation exchange capacity (CEC) of the MMT was found to be $73 \mathrm{meq} / 100 \mathrm{~g}$ (Mai and Yu 2006). The TGA curve for CA-MMT exhibits a strong exotherm near $300{ }^{\circ} \mathrm{C}$. This exotherm can be assigned to the decomposition of the exchanged cetyl ammonium ions into the clay galleries. Figure 4 shows the effect of the clay content on the $T_{\mathrm{g}}$. The increase in the $T_{\mathrm{g}}$ of the nanocomposites in comparison with the original unsaturated polyester can be attributed to improved adhesion between the polymer and the layered silicate surfaces and it is also due to the decrease in relative concentration of styrene with increasing clay content (Sanchez et al. 2000).

\section{Mechanical properties}

The load at ultimate strength for tensile studies increases with the clay content up to $3 \%$ (w/w) loading, as shown in 

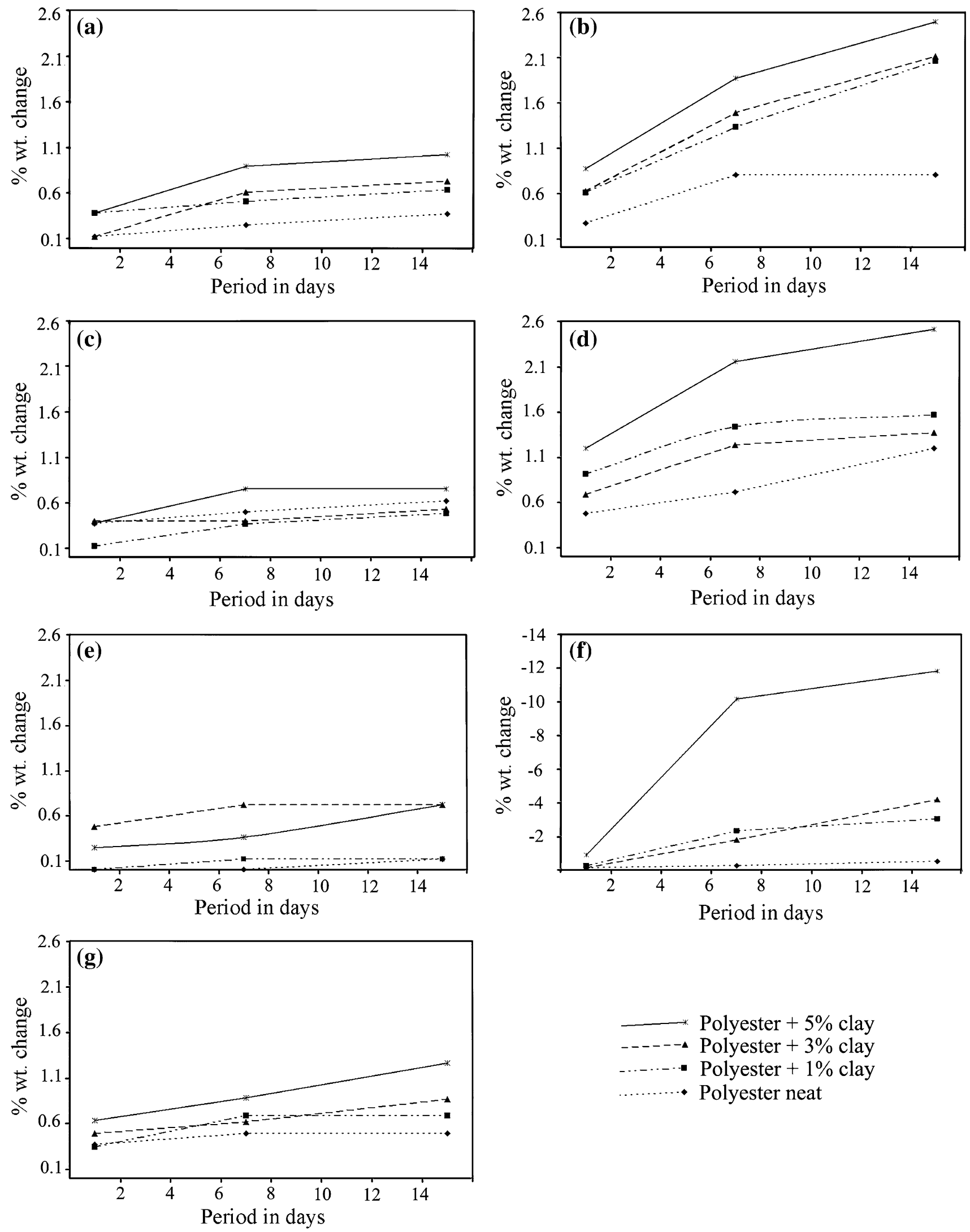

Polyester $+5 \%$ clay

Polyester $+3 \%$ clay

- Polyester $+1 \%$ clay

- Polyester neat

Fig. 7 Shows the weight change of composites against period in different chemical environment. a $8 \%$ acetic acid, b $40 \%$ nitric acid, c $10 \%$ hydrochloric acid, $\mathbf{d} 10 \%$ aqueous ammonia, e $20 \%$ sodium carbonate, $\mathbf{f} 10 \%$ sodium hydroxide, $\mathbf{g}$ water 
Fig. 5a. Extension at maximum load, tensile stress at maximum load, tensile strain at maximum load and tensile modulus are shown in Fig. 5b-e, respectively. It is observed that the extension at maximum load is higher for the loading of $3 \%(\mathrm{w} / \mathrm{w})$ clay. The tensile stress on the composites increases with the clay content up to $5 \%(\mathrm{w} / \mathrm{w})$ loading, indicating the reinforcing capacity and increased adhesion of clay particles. The tensile strain at maximum load decreases with the filler content up to $5 \%(\mathrm{w} / \mathrm{w})$. Further increase in the clay content may lead to higher crosslink density and thus the strain at maximum load would ease. The tensile modulus of the composites increases with the clay content up to $5 \%(\mathrm{w} / \mathrm{w})$ loading, since clay is more rigid than the matrix resin.

The load at ultimate strength for flexure studies has increased with the clay content up to $5 \%(\mathrm{w} / \mathrm{w})$ loading, as shown in Fig. 6a. Flexure extension at maximum load, flexure strength at maximum load, flexure strain at maximum load and flexure modulus at maximum load are shown in Fig. 6b-e, respectively. It is observed that the extension at maximum load was found to be high for the loading of $5 \%(\mathrm{w} / \mathrm{w})$ clay. The flexure strength of the composites increases with the clay content up to $5 \%(\mathrm{w} / \mathrm{w})$

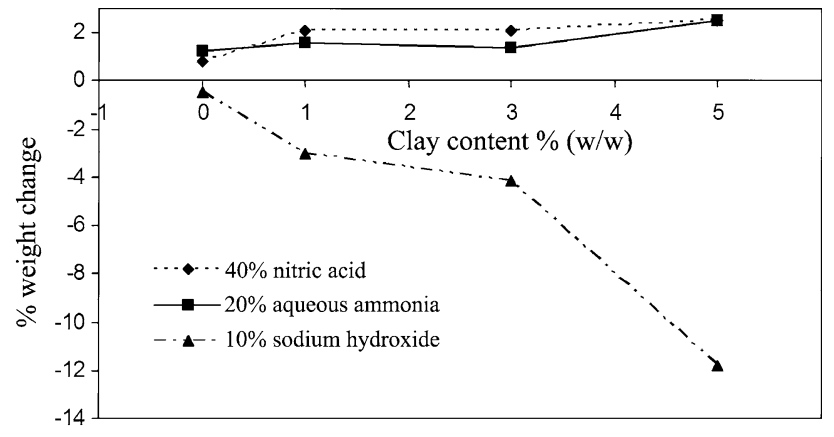

Fig. 8 Shows the \% weight change with respect to clay content of composites in solutions for 15 days
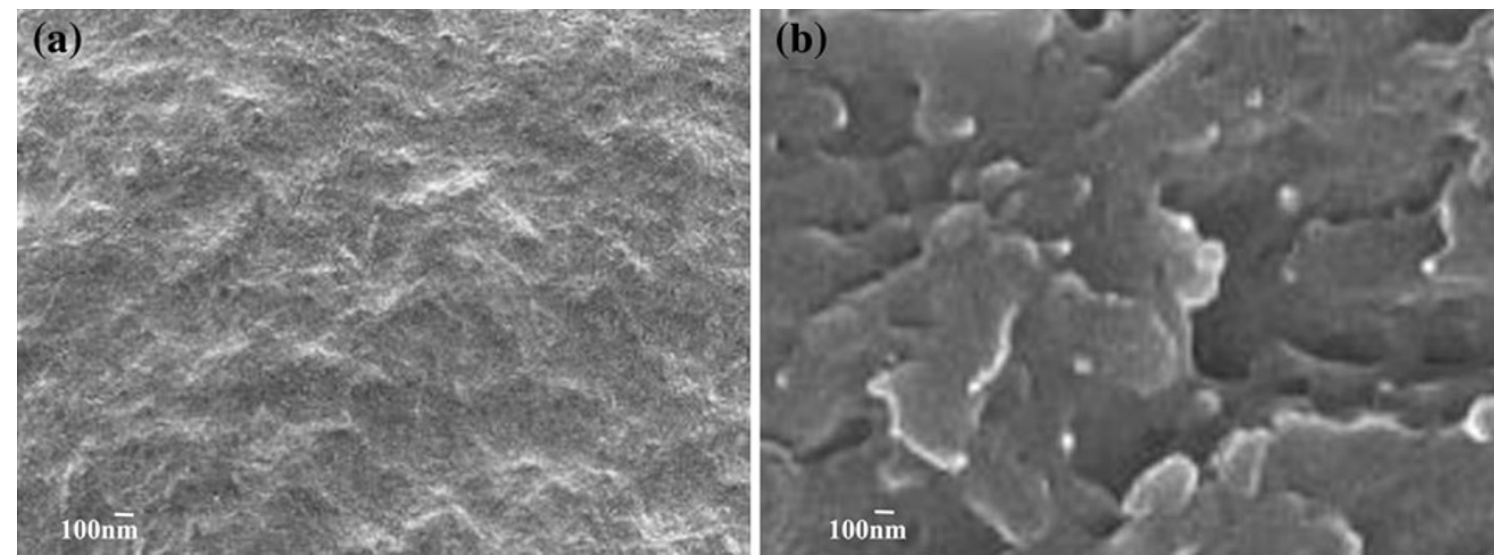

loading, indicating the high reinforcing capacity due to the well-adhered clay particles. The flexure strain at maximum load decreases with the filler content up to $5 \%$ (w/w). Further increase in the clay content may lead to higher crosslink density and thus the strain at maximum load would decrease. The flexure modulus of the composites increases with the clay content up to $5 \%(\mathrm{w} / \mathrm{w})$ loading, since clay is more rigid than the matrix resin.

Chemical resistance measurements

The weight gain/loss for the neat unsaturated polyester and organically modified clay-filled unsaturated polyester composites with various chemicals are shown in Fig. 7. Barring sodium hydroxide, in all studied chemicals there is increase in weight with period and clay content. The swelling of composites indicates the expandable nature of the clay due to absorption of solvent water in their interstices. This is amply indicated by the maximum weight gain $(2.5 \%)$ attained in $40 \%$ nitric acid and $10 \%$ aqueous ammonia (Fig. 7b, d). In contrast, alkaline solution $10 \%$ sodium hydroxide has effected considerable weight loss in the matrices $(14 \%)$ indicating heavy cation exchange within the clay matrices replacing heavier ions of aluminium and iron with lighter sodium ions (Fig. 7f). Intermediate characteristics have been observed in all other solutions (Fig. 7a, c, e, g). It could be noted that the weight loss or gain suffered by the composites is in direct proportion to the amount of clay introduced in polymer matrices as observed in Fig. 8.

\section{Morphology}

SEM micrographs for neat unsaturated polyester and polyester with $5 \%(\mathrm{w} / \mathrm{w})$ clay are represented in Fig. 9. The neat unsaturated polyester and clay-filled unsaturated

Fig. 9 SEM image of neat polyester (a) and polyester $+5 \%$ clay (b) 
polyester matrix systems reveal the smooth, glassy and homogeneous morphology due to the efficient interaction between the unsaturated polyester organo-modified clay.

\section{Conclusion}

$\mathrm{X}$-ray diffraction analysis leads to conclude that modification of MMT with sodium and tetradecyltrimethylammonium ions influences the average $d$-spacing. Thermogravimetric analysis shows the extent of cation exchange of the modified clay to be $73 \mathrm{meq} / \mathrm{g}$. The $T_{\mathrm{g}}$ value is found to be maximum for the composites with maximum clay content, indicating an improvement in adhesion between the polymer and the layered silicate surfaces.

The neat unsaturated polyester composite is found to exert better chemical resistance compared to the clay composites. The highly expandable montmorillonite clay has caused maximum swelling in nitric acid and aqueous ammonia in contrast to maximum weight loss in sodium hydroxide due to its high CEC. SEM micrographs of surfaces of the neat unsaturated polyester and clay-filled unsaturated polyester matrix systems reveal a smooth, glassy and homogeneous morphology due to the efficient interaction between the unsaturated polyester organomodified clay. The mechanical properties, viz. tensile and flexural characteristics have considerably increased with clay content. These polymer clay composites could be effective with positive mechanical and thermal properties against non-aqueous solvents.

Open Access This article is distributed under the terms of the Creative Commons Attribution License which permits any use, distribution, and reproduction in any medium, provided the original author(s) and the source are credited.

\section{References}

Annual book of ASTM Standards (1989) American Society for Testing and Materials, vol 8. Philadelphia

Chozhan CK, Alagar M, Sharmila RJ, Gnanasundaram P (2007) Thermo mechanical behaviour of unsaturated polyester toughened epoxy-clay hybrid nanocomposites. J Polym Res 14: 319-328

Fu X-A, Qutubuddin S (2004) Synthesis of unsaturated polyester-clay nanocomposites using reactive organoclays. Polym Eng Sci 44:345-351

Kornmann X, Berglund LA, Sterte J, Giannelis EP (1998) Nanocomposites based on montmorillonite and unsaturated polyester. Polym Eng Sci 38:1351-1358

Lee HS, Fishman D, Kim B, Weiss RA (2004) Nano-composites derived from melt mixing a thermotropic liquid crystalline polyester and zinc sulfonated polystyrene ionomers. Polymer 45:7807-7811

Liqun Xu, James Lee L (2004) Effect of nanoclay on shrinkage control of low profile unsaturated polyester (UP) resin cured at room temperature. Polymer 45:7325-7334

Liqun Xu, James Lee L (2005) Kinetic analysis and mechanical properties of nanoclay reinforced unsaturated polyester (UP) resins cured at low temperatures. Polym Eng Sci 45:496-509

Mai Y, Yu Z-Z (2006) Polymer N, 1st edn. Woodhead, Cambridge, England

Mark HF, Bikales NM, Overberger CG, Menges G (1988) Encyclopedia of polymer science and engineering, vol 12 . Wiley, New York

Mironi-Harpaz I, Narkis M, Siegmann A (2005) Nanocomposite systems based on unsaturated polyester and organo-clay. Polym Eng Sci 45:174-186

Sanchez EMS, Zavaglia CAS, Felisberti MI (2000) Unsaturated polyester resins: influence of the styrene concentration on the miscibility and mechanical properties. Polymer 41:765-769

Suh DJ, Lim YT, Park OO (2000) The property and formation mechanism of unsaturated polyester-layered silicate nanocomposite depending on the fabrication methods. Polymer 41: $8557-8563$

Tjong SC (2006) Structural and mechanical properties of polymer nanocomposites. Mater Sci Eng Res 53:73-197 